\title{
Possibilidades pedagógicas do uso das tecnologias móveis no ensino de Matemática na perspectiva da m-learning
}

\author{
Pedagogical possibilities of the use of mobile technologies in the teaching of \\ Mathematics in the perspective of m-learning
}

Jenekésia Lins da Silva ${ }^{1}$

Carloney Alves de Oliveira²

\section{Resumo}

O presente artigo apresenta uma pesquisa sobre a utilização de um aplicativo (App) em aulas de Matemática numa Escola Estadual no município de Matriz de Camaragibe, o qual propiciou ao aluno um ambiente para socialização do conhecimento na perspectiva de uma aprendizagem móvel a partir das abas disponibilizadas. $O$ objetivo geral desta pesquisa foi refletir sobre o uso das tecnologias móveis (TM) no ensino de Matemática na perspectiva do m-learning de modo a promover a socialização do conhecimento entre professor e aluno. Para alcançar o objetivo proposto utilizou-se os estudos de Coll e Monereo (2010), Saccol (2011) e Moran (2013). A pesquisa foi desenvolvida por um estudo exploratório, numa abordagem qualitativa. Os dados foram coletados através de entrevistas com professores e alunos. Os sujeitos envolvidos apresentaram os resultados a partir da navegabilidade em utilizar o App desenvolvido com o apoio da plataforma fábrica de aplicativos em sala de aula, e reconheceram que este App abriu caminhos para a disseminação do conhecimento a partir de pesquisas, textos e exercícios de maneira atrativa e dinâmica.

Palavras-chave: Ensino de Matemática. M-learning. TM.

\section{Abstract}

The purpose of this paper is to present our research conducted on the use of the application (App) in Mathematics classes at a State School in the municipality of Matriz de Camaragibe, which provided the student with an environment for socialization of knowledge in the perspective of mobile learning from the tabs available. The general objective of this research was to reflect on the use of mobile technologies (TM) in mathematics teaching from the perspective of m-learning in order to promote the

\footnotetext{
${ }^{1}$ Mestre em Ensino de Ciências e Matemática (UFAL). Experiência na área de Educação, com ênfase em Avaliação da Aprendizagem, robótica educacional e tecnologias móveis. jenekesialins@hotmail.com

2 Doutor em Educação (UFAL). Professor Adjunto do Curso de Pedagogia na área de Saberes e Metodologias do Ensino da Matemática (UFAL). Professor vinculado ao Programa de PósGraduação em Ensino de Ciências e Matemática (PPGECIM) da UFAL. Membro do Grupo de Pesquisa em Educação Matemática. carloneyalves@gmail.com
} 
socialization of knowledge between teacher and student. In order to reach the proposed objective we used the studies of Coll and Monereo (2010), Saccol (2011) and Moran (2013). The research was developed by an exploratory study, in a qualitative approach. The data collected through interviews with teachers and students. The subjects involved presented the results from the navigability in using the App developed with the support of the website of the application factory in the classroom, and recognized that this App opened paths for the dissemination of knowledge from research, texts and exercises of attractive and dynamic way.

Keywords: Teaching of Mathematics. M-learning. TM.

\section{Introdução}

A partir da prática pedagógica em sala de aula em uma Escola Estadual no município de Matriz de Camaragibe - AL sentimos a necessidade de buscar novos recursos que possibilitassem a melhoria no processo de ensino e aprendizagem em aulas de Matemática, tendo em vista, que os alunos estão sempre conectados através de celular, tablets ou smartphones.

Diante desses dispositivos móveis trazidos por alunos, percebemos que é possível ampliar a prática pedagógica e auxiliar nos processos de ensino e de aprendizagem, utilizando aplicativos (App) que podem ser desenvolvidos com o objetivo de propor uma interação em sala de aula como o produto educacional elaborado, intitulado App Matemática Interativa.

Utilizou-se a plataforma fábrica de aplicativos para desenvolver o App Matemática Interativa, no qual ofereceu aos sujeitos envolvidos recursos que vão além da sala de aula, de maneira fácil e rápida, potencializando e abrindo novas possibilidades para pesquisas e discussões com temas que realmente promoveram a troca de experiências e interações com os recursos disponibilizados.

O produto educacional App Matemática Interativa foi criado com o intuito de auxiliar o professor e aluno nos processos de ensino e aprendizagem em Matemática, principalmente no que concerne 0 assunto relacionado a Trigonometria, tendo em vista que era o conteúdo que estava sendo estudado em sala de aula naquele momento, no qual possibilitou ao professor e aluno uma nova forma de ensinar e aprender Matemática de maneira eficaz e proativa. 
Atualmente, as TM vêm expandindo com diversas finalidades, destacandose a comunicação, interação, informação e aprendizagem. As TM por sua vez, faz parte da vida cotidiana dos jovens, onde os mesmos utilizam para sua comunicação, com seus aliados através de aplicativos de bate-papos e jogos. Neste sentido, há um quadro favorável para inseri-la no contexto educativo, pois a massificação da utilização das TM destaca-se aos usuários que se encontram em idade escolar.

As TM com o uso do App tornaram-se um recurso utilizável pelo professor, aluno e mostra que é possível trabalhar de formas diferentes, com um olhar diferenciado para esta área, tornando-o assim, uma aula mais criativa e que tenha um resultado com valor significativo na aprendizagem de cada aluno.

Desse modo, na pesquisa realizada buscamos responder o seguinte questionamento: Como as TM podem contribuir nos processos de ensino e aprendizagem em matemática, na perspectiva do mobile learning, no intuito de promover interação entre professor e aluno?

A pesquisa foi desenvolvida por meio de estudo exploratório, o qual propiciou uma relação mais próxima entre o pesquisador e o informante, onde 0 pesquisador participou da realidade investigada. A pesquisa foi caracterizada do tipo qualitativa, tendo em vista o contato direto do pesquisador com o informante, permitindo explicar o porquê dos fenômenos detectados em determinado evento. Os dados foram coletados através das entrevistas com professores e alunos. Os dados da pesquisa foram mediados pela análise textual dos professores e alunos.

Por fim acreditamos que o App possibilita ao professor e aluno uma nova forma de aprendizagem na perspectiva m-learning, de forma, que o acesso potencializa novas informações e interações que se sobrepõem a um complemento já estudado em sala de aula. Contudo, o uso do App no contexto escolar ajudou ao professor e aluno a ensinar e aprender, estudar em qualquer hora e em qualquer lugar de forma acessível, atrativa e dinâmica. 


\section{O uso das tecnologias móveis na educação}

A partir dos avanços tecnológicos, percebe-se que as TM conhecidas pelos dispositivos celular, tablets e smartphones vêm trazendo contribuições na sociedade contemporânea, abrindo novos caminhos para as informações, comunicações e interação no mundo social e no contexto escolar, portanto, no cenário educativo percebe-se que tais tecnologias influenciam de maneira que possibilita a interação entre professor e aluno, ampliando e apresentando inúmeros recursos como: aplicativos, jogos, calculadora e dentre outros, para auxiliar no processo de ensino e de aprendizagem.

O professor deve estar atento às inovações tecnológicas, uma vez que a evolução tecnológica amplia as possibilidades de informações e comunicações. $O$ professor não pode estar somente atento, é preciso está preparado para a utilização das TM na sala de aula, de maneira que seu preparo potencialize o desejo de incluí-lo em sua prática e situá-los efetivamente de maneira reflexiva e crítica, consolidando as novas práticas de educar, aprender e de pensar. Moran (2013, p. 13) destaca que:

Uma educação inovadora se apoia em um conjunto de propostas com alguns grandes eixos que the servem de guia e de base: o conhecimento integrador e inovador, o desenvolvimento da autoestima e do autoconhecimento (valorização de todos); a formação de alunos empreendedores (criativos, com iniciativa) e a construção de alunos-cidadãos (com valores individuais e sociais).

O uso das TM na educação pode facilitar o processo de ensino e de aprendizagem de maneira flexível. Moran (2013, p. 14) ainda defende que "o uso da mobilidade na educação nos libertas dos espaços e dos tempos rígidos, previsíveis e determinados". Portanto, o uso das tecnologias pode flexibilizar o tempo de estudo dos alunos de forma eficiente dentro e fora do contexto escolar.

No contexto educacional, com o uso das TM, é possível promover diversas estratégias para ensinar e aprender, nesse sentido, o professor precisa criar ambiente propício, ao mesmo tempo desafiador e interessante para o aluno, pois 
é necessário inovar as práticas pedagógicas e oferecer metodologias diversificadas para o processo de ensino e de aprendizagem utilizando a tecnologia, a fim de aprimorar sua relação com a realidade do aluno.

\subsection{Aprendizagem Móvel (m-learning) como um elo na educação}

Diante as prerrogativas apresentadas sobre o uso das TM na educação e como recurso facilitador para o processo de construção do conhecimento, surge o seguinte questionamento. Como se dá a aprendizagem dos sujeitos através da mobilidade? Para Saccol (2011, p. 6) "aprender em processos de mobilidade implica abrir-se as potencialidades que essas tecnologias oferecem", portanto, os dispositivos têm grande influência na educação, a sua utilização contribui para um desenvolvimento de conteúdos, no qual permite ao professor utilização de diversos recursos para auxiliar no processo de ensino e de aprendizagem.

O uso das TM na sala de aula pode contribuir para uma aprendizagem interativa, pois as mesmas oferecem diversas estratégias para facilitar o processo de ensino e de aprendizagem (SILVA; OLIVEIRA, 2015). Sabemos que o uso dessas TM na sala de aula, não vai melhorar a educação e sim contribuir de forma estimulante para que o aluno tenha prazer em aprender e facilitar 0 processo de transmissão de conteúdo. Coll e Monereo (2010, p. 28) relatam que a aprendizagem móvel:

[...] abre imensas possibilidades para se empreender trabalhos de campo, trocar reflexões, analisar conjuntamente atuações profissionais que estejam ocorrendo neste mesmo instante ou para integrar em um trabalho de equipe de pessoas geograficamente afastadas entre si.

Sendo assim, percebemos que a aprendizagem móvel permite a acessibilidade e a adaptabilidade aos usuários a buscar conhecimento em qualquer hora e em qualquer lugar. Saccol $(2011$, p. 25) define a aprendizagem móvel como um ambiente, 
apoiado pelo uso de tecnologias da informação e comunicação móveis e sem fio, cuja característica fundamental é a mobilidade dos aprendizes, que podem estar distante uns dos outros e também de espaços formais de educação, tais como salas de aula, salas de formação, capacitação e treinamento ou local de trabalho.

A aprendizagem móvel é destacada pelo uso das TM que permite várias formas de aprender em qualquer hora e lugar. Ou seja, o aluno não precisa se limitar apenas o espaço físico na escola para adquirir conhecimentos, existem diversas formas de enriquecer a aprendizagem em seu próprio mundo.

\subsection{Possibilidades pedagógicas do uso das TM em sala de aula}

Os dispositivos das TM como tablets, smartphones e celular já fazem parte do cotidiano dos alunos em sala de aula que muitas vezes causam desconfortos pelo seu uso. Percebemos que muitos professores veem tais recursos como um problema na sala de aula e que muitas vezes não há interesse por parte dos alunos em querer estudar. Nesse caso, o professor não pode ver esses dispositivos como um problema e sim um recurso criativo para o processo de ensino e de aprendizagem.

Dessa forma, Saccol (2011, p. 30) destaca que "em boa parte das instituições formais de ensino o uso de telefones celulares são restritos, por uma espécie de convenção social". Nesse sentido, percebe-se que o aluno tem uma rotina com a utilização do celular por estar conectado em sala de aula, assim, a escola não pode proibir o seu uso, onde estes dispositivos podem contribuir de maneira que os envolve no processo de construção do conhecimento.

Saccol (2011, p. 31), ainda destaca que:

Se adotarmos uma concepção epistemológica de que o conhecimento é fruto de uma construção do indivíduo feito em colaboração com professores e colegas, devemos selecionar tecnologias que permitam interação intensiva entre as pessoas, por exemplo, por meio de ambientes virtuais que disponibilizem fóruns, chats, espaços para compartilhamento de projetos arquivos de interesse comum, etc. 
Para um desenvolvimento de uma aprendizagem é preciso uma dinamização dos conceitos científicos, através de recursos tecnológicos como celular e tablets para facilitar a construção do conhecimento, pois a educação escolar possibilita ao aluno um avanço do conceito do senso comum "conceito cotidiano" para compreender os acontecimentos da sociedade.

Saccol (2011, p. 31), destaca que "os dispositivos móveis não foram desenhados especificamente para atividades educacionais". Portanto, professores e gestores precisam se adequar a realidade do aluno, o uso excessivo aumenta o desafio no âmbito escolar, mas os educadores precisam inserir essas tecnologias como auxílio pedagógico para o processo de ensino e de aprendizagem, para que os alunos possam pesquisar, trocar informações e, além disso, a comunicação e possibilitar um elo entre o conhecimento adquirido e o conhecimento do senso comum.

Em contrapartida, o uso do celular, tablets e smartphones pode tornar-se um desafio na escola, porém, percebemos que muitos professores não estão preparados para se adaptar a esta nova realidade, sabendo que o uso dessas tecnologias é um recurso para auxiliar na construção do conhecimento que possibilita o processo de ensino e aprendizagem de forma criativa.

Com a adoção destes dispositivos em sala de aula, como recurso auxiliar no processo de construção do conhecimento, há uma possibilidade de ampliação de recursos para o aluno ir em busca desse conhecimento. As TM disponibilizam vídeos, editor de textos simulação, página do Facebook, exercício, história em quadrinhos e etc, sendo possível uma adoção de uma biblioteca móvel que permite ao aluno a oportunidade de aprender em qualquer hora e em qualquer lugar.

\subsection{App como estratégia didática nas aulas de matemática}

Com a inserção das TM na sala de aula, o professor pode utilizar aplicativos que facilitem o processo de ensino e de aprendizagem, sendo assim, a 
fábrica de aplicativos pode ser um recurso como suporte pedagógico para as aulas de Matemática.

Durante as aulas de Matemática, alguns alunos sentem-se insatisfeitos com relação a disciplina, por não gostar e ter dificuldade em aprender, e percebemos que o ensino de Matemática está baseado de forma tradicional, onde ensinam apenas com livros, resoluções de problemas, e muitas vezes o ensino se dar pelo meio transmissor e receptor, ou seja, o professor transmite e o aluno recebe como forma de uma aprendizagem bancária.

Por outro lado, com o advento das TM que a cada dia vão sendo inseridas no mundo atual e vem ampliando a forma de comunicação, interação entre os usuários e, modificando a forma de pensar no meio social, na sala de aula não poderia ser diferente, o uso das TM pode se tornar um desafio, pois, o professor precisar se atualizar e aproveitar esse momento de integração trazido por alunos para uma mudança na prática pedagógica para contribuir no processo de construção do conhecimento. Nesse sentido, percebe-se que os alunos estão sempre conectados através de celular, tablets e smartphones que muitas vezes ao usar esses dispositivos estão conversando ou pesquisando assuntos de seus interesses.

\section{Construindo o App Matemática Interativa com o apoio da} fábrica de aplicativos

A fábrica de aplicativos pode trazer grandes possibilidades para o professor e o aluno para criação de App para utilizar em dispositivos móveis como celular e tablets, no qual pode favorecer uma aprendizagem. Portanto, o uso das TM possibilita ao aluno produzir conhecimento em qualquer hora e em qualquer lugar. Utilizar a fábrica de aplicativos é uma forma de dar continuidade ao trabalho desenvolvido em sala de aula, no qual, esse recurso poderá motivar os alunos a pesquisar mais sobre o conteúdo estudado e aprender de forma criativa e interativa, além disso, o professor deverá valorizar o conhecimento que o aluno traz do seu cotidiano, a partir das pesquisas realizadas pelas TM. 
Adotar a fábrica de aplicativos como suporte pedagógico em aulas de Matemática pode se tornar um grande desafio para o professor, pois, o professor precisa alimentar o App para atender as necessidades dos alunos de forma que são necessárias novas atitudes para que o processo de ensino e de aprendizagem seja prazeroso.

A fábrica de aplicativos é uma plataforma brasileira que permite a criação de App para dispositivos móveis (tablets, celulares e smartphones). Essa tecnologia permite a qualquer pessoa sem nenhum conhecimento de programação, criar e compartilhar aplicativos de forma rápida e fácil.

O uso da fábrica de aplicativos como suporte pedagógico em aulas de Matemática, pode promover uma nova forma de pensar e interagir através das TM que possibilita ao aluno apropriar-se do seu próprio conhecimento e tais tecnologias necessita ser entendida pelos professores como parte constitutiva do processo de ensino e de aprendizagem.

A fábrica de aplicativos foi lançada em outubro de 2011 com o principal objetivo da utilização das TM e como porta principal de entrada para tecnologias digitais. A fábrica de aplicativos conta com mais de 200 mil App criados em 120 países, disponibiliza dois serviços distintos: gratuito e pago, sendo o pago com variáveis preços, devido à quantidade de recursos disponíveis que o usuário pode requerer e o gratuito com recursos básicos.

Para criação de um App na fábrica de aplicativos não é necessário ter conhecimento de programação, pois a plataforma indica os primeiros passos para a criação do App. É necessário que o usuário faça um cadastro na plataforma (o usuário tem que ter conta em facebook) e criar uma senha de validação. A figura 1 mostra o primeiro passo sobre a plataforma para criação do App. 
Figura 1: - Página de Abertura da Plataforma fábrica de aplicativos

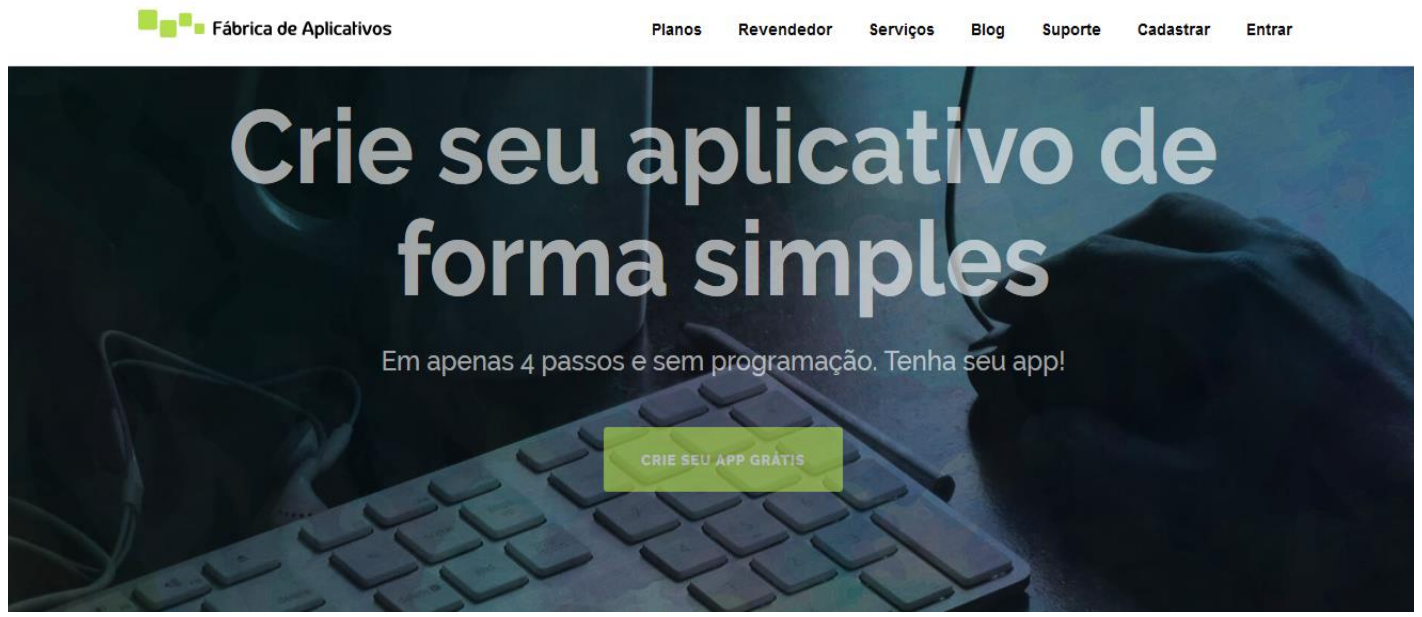

Fonte: http://fabricadeaplicativos.com.br/ ano (2016)

Clicando nessa opção, a plataforma fábrica de aplicativos irá direcionar o usuário para uma nova área para realização de um cadastro (Figura 2), nesta opção o usuário irá se cadastrar seu e-mail através da conta do facebook e criar uma senha. Ao se cadastrar o usuário terá que assinar um termo de uso.

Ao cadastrar o e-mail o usuário receberá um e-mail com instruções para acessar sua conta na plataforma e confirmação. Clicando na opção "Confirmar $e$ mail' o usuário será direcionado para página principal da plataforma para cadastrar a senha e o nome do usuário.

Figura 2: Cadastro do nome de usuário e senha.
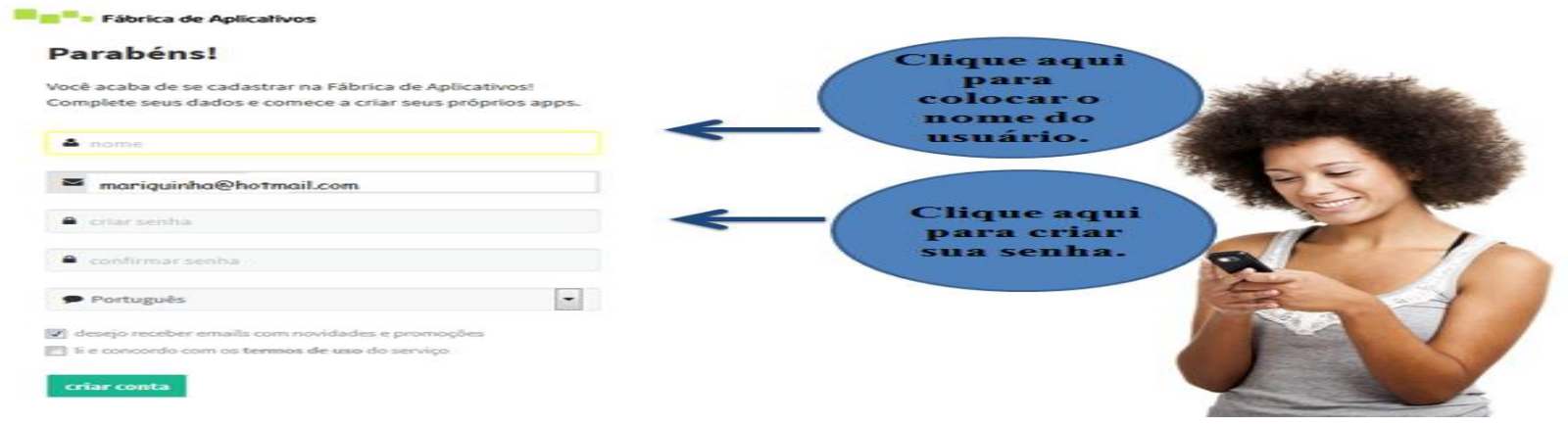

Fonte: http://dashboard.fabricadeaplicativos.com.br/\#signup ano (2016)

Após colocar o nome e senha a plataforma pede ao usuário para clicar na opção "criar conta”. Ao clicar nessa opção a plataforma direciona ao usuário para 
uma nova área, na qual o usuário pode escolher a cor do tema, layouts do menu e imagens do tema que está disponível para abertura do App (figura 3)

Figura 3: Design com a escolha da cor do tema para abertura do App.

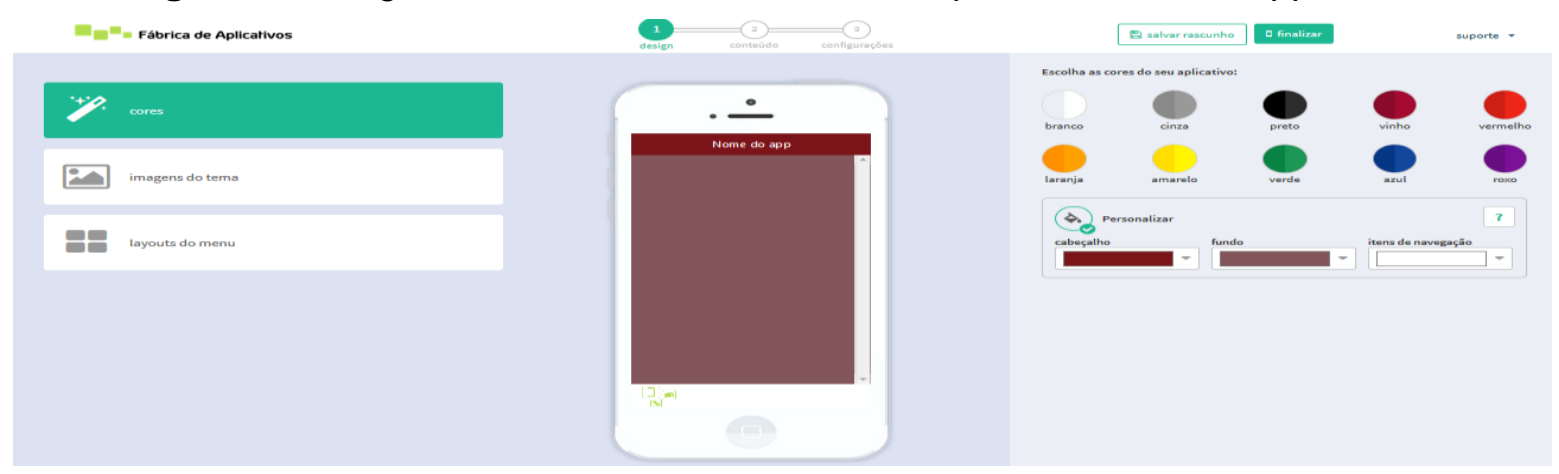

Fonte: http://portal2.fabricadeaplicativos.com.br/applications/edit/1710423 ano (2016)

Figura 4: Design dos Layout para abertura do App.

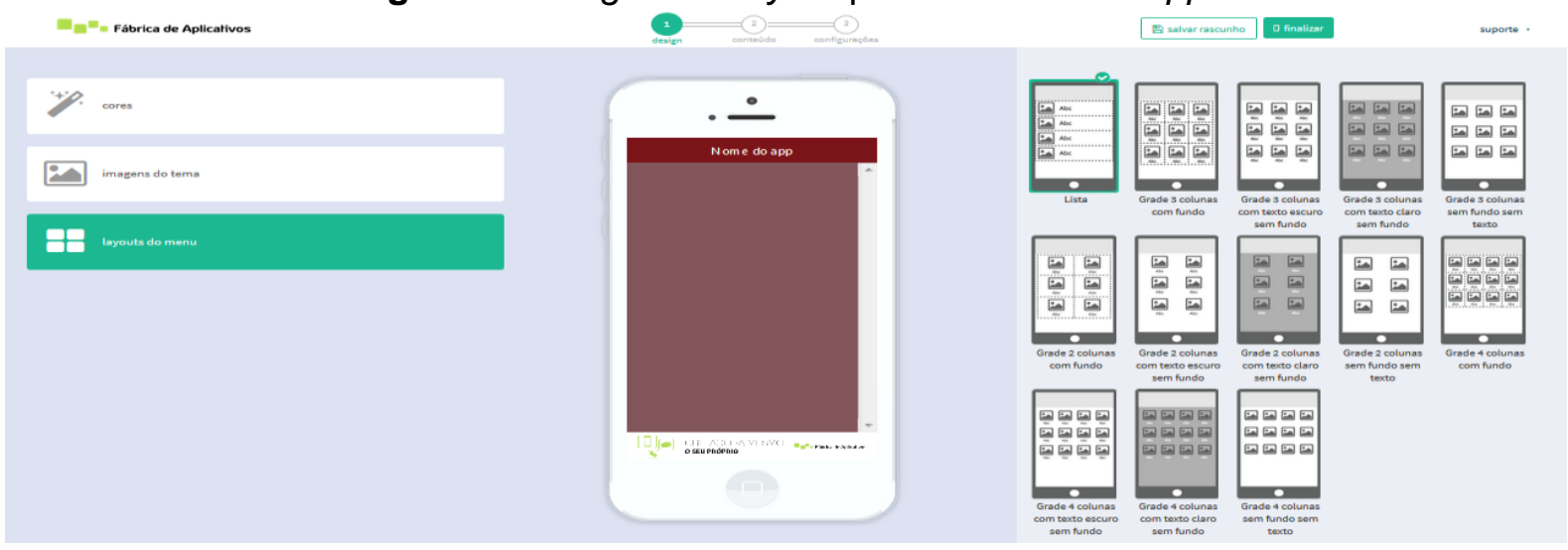

Fonte: http://portal2.fabricadeaplicativos.com.br/applications/edit/1710423 ano (2016)

Ao concluir o design de abertura o usuário precisa clicar na opção 2 (conteúdo) da plataforma para organizar as abas que desejar utilizar em seu App. Clicando nessa opção o usuário precisa arrastar as abas para dentro do celular conforme deseja organizar os conteúdos. (figura 5) 
Figura 5: Abas disponíveis para adicionar os conteúdos.

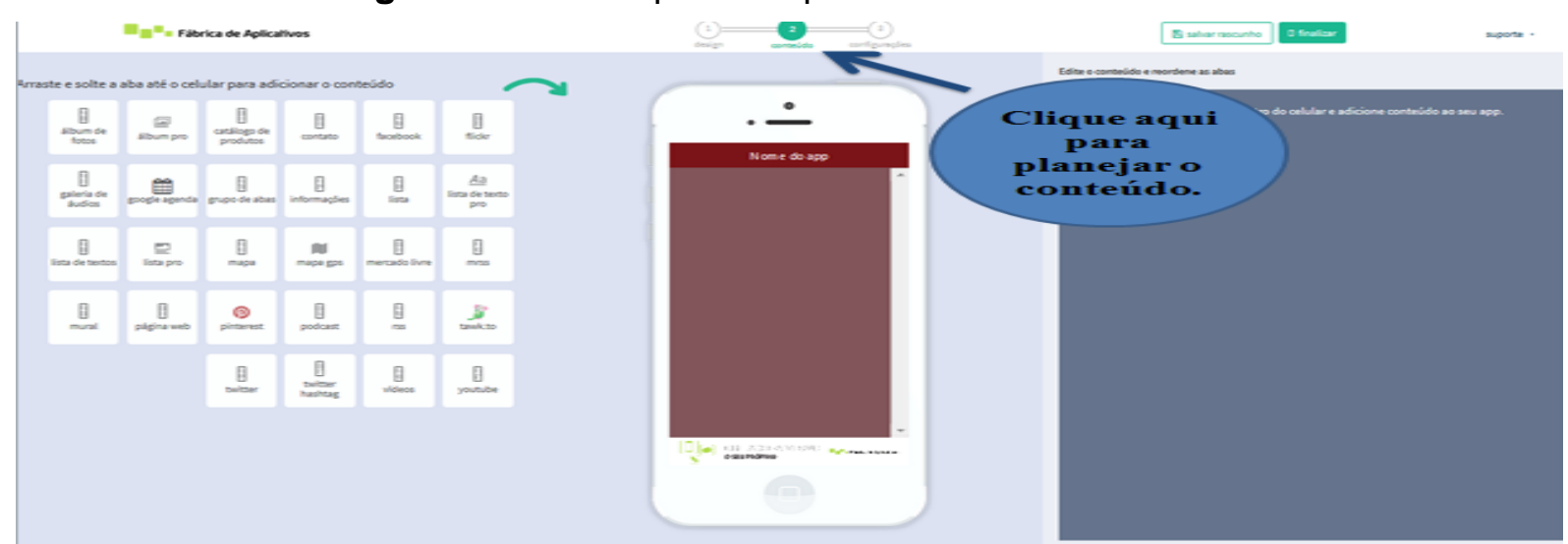

Fonte: http://portal2.fabricadeaplicativos.com.br/applications/edit/1710423 ano (2016)

Concluindo o desenvolvimento para a tela de abertura do App, selecionamos algumas delas para ter o conhecimento e não utilizar a aba errada para o objetivo no qual deseja realizar.

1. Álbum de Fotos: permite criar galeria de imagens no App. Para disponibilizar imagens neste recurso é necessário que o usuário envie uma imagem de cada vez colocando uma legenda para cada uma, também é possível exportar imagens de páginas da Web;

2. Informações: o usuário pode adicionar informações sobre diversos conteúdos, reuniões, e etc;

3. Listas: permite adicionar textos e exercícios, nele é necessário que envie imagens e também há uma opção de enviar listas sem imagens;

4. Redes sociais: possibilita ao usuário exportar conteúdos disponíveis nas redes sociais (facebook) e disponibilizar links de grupos criados no facebook para trocas de informações, lembrando que essa página funciona somente com páginas públicas;

5. Vídeos: permite enviar vídeos até $12 \mathrm{MiB}$ na plataforma como também disponibilizar links de simulações;

6. Youtube: permite adicionar vídeos e canais do Youtube na plataforma.

Para atender o objetivo proposto deste trabalho, selecionamos algumas abas para atender o objetivo da disciplina Matemática no processo de construção 
do conhecimento, dentre elas: lista de textos, lista de exercício, informações, (figura 6)

Figura 6: Planejando o conteúdo.

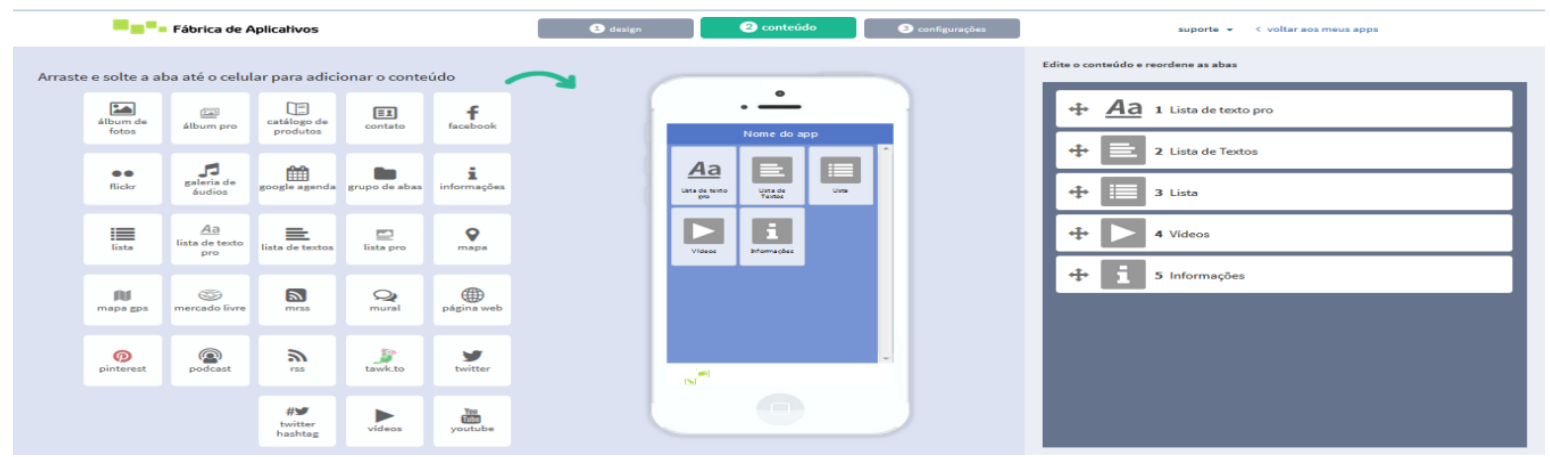

Fonte: http://portal2.fabricadeaplicativos.com.br/applications/edit/1710423 ano (2016)

Ao concluir, a plataforma direciona o usuário para a opção "configuração", (figura 7) no qual está disponível para o usuário colocar o nome do App, criar o nome da página do App e salvá-lo na plataforma. O App será disponibilizado na galeria da plataforma para apreciação do público e estará disponível para instalação em dispositivos móveis ou adicioná-lo à tela inicial do celular, tablets ou smartphones.

Figura 7: Perfil para publicação

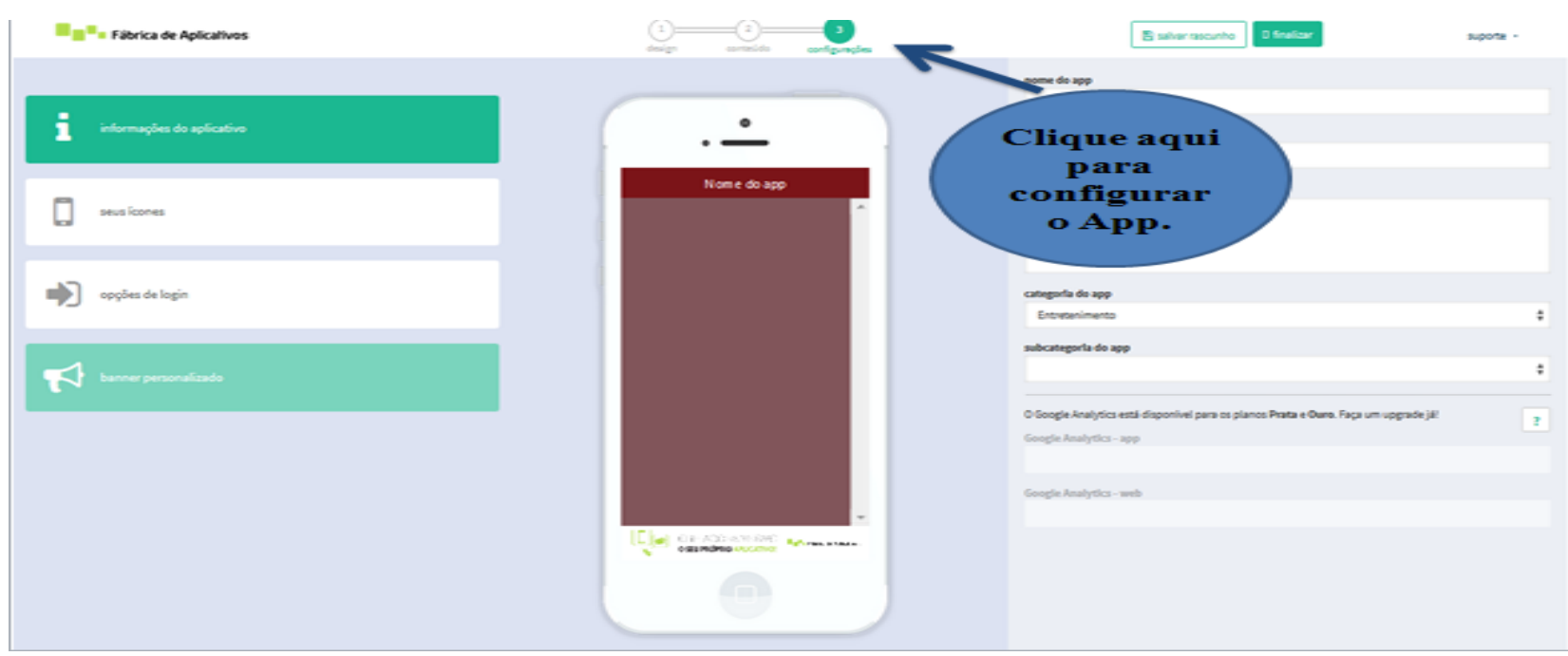

Fonte: http://portal2.fabricadeaplicativos.com.br/applications/edit/1710423 ano (2016) 
Após a publicação do $A p p$ na plataforma fábrica de aplicativos, o App estará pronto para uso em qualquer hora e em qualquer lugar, conforme figura 8.

Figura 8: Interfaces disponibilizadas no App Matemática Interativa

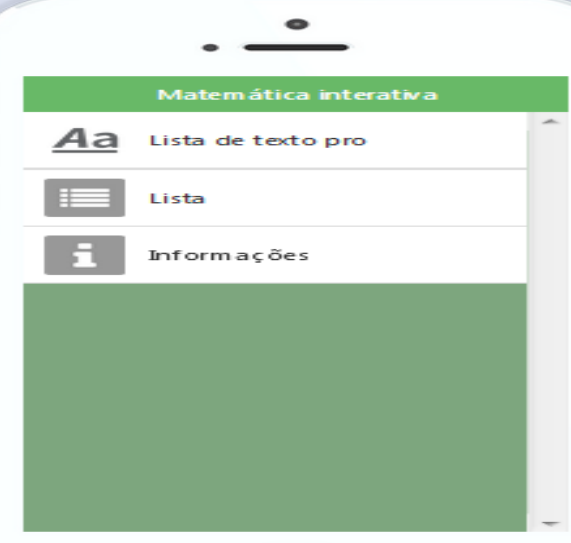

Fonte: http://galeria.fabricadeaplicativos.com.br/matematica interativa ano (2016)

A limitação da funcionalidade do App é desenvolvida em dispositivos com telas maiores (tablets, smartphones, celulares), portanto, o App só pode ser visualizado quando for instalado ou adicionando a tela inicial desses dispositivos.

Ao concluir o App na fábrica de aplicativos, o usuário tem a liberdade em disponibiliza-lo no play-store e dentre outras lojas, pagando uma tarifa de acordo com a política de cada loja para divulgação. Se o moderador preferir não publicar o App, a fábrica de aplicativos possibilita ao usuário adicioná-lo à tela principal do celular como qualquer outro link de sites e poderá utilizar normalmente.

Os recursos destacados para utilização do App possibilitam ao professor uma criação de estratégias que venham dar um suporte em aulas de Matemática, tornando-o assim a aula mais dinâmica, atrativa e com uma aprendizagem prazerosa. 


\section{Metodologia}

A pesquisa foi desenvolvida por meio de um estudo de exploratório (GIL, 2008) e caracterizada do tipo qualitativa (GODOY, 1995) em uma escola estadual no município de Matriz de Camaragibe - AL, tendo como sujeitos envolvidos 30 (trinta) alunos selecionados, ou seja, aqueles que primeiros foram inscritos após convite, e 5 (cinco) professores de Matemática que lecionam na escola.

Para coleta de dados, utilizou-se a entrevista semiestruturada com alunos e professores, para um melhor aprofundamento e registros da pesquisa e acúmulo das informações sobre os fatos. As entrevistas com alunos foram em horário de aula e com professores em momentos oportunos para não atrapalhar seu horário de atividades. Os nomes dos entrevistados foram mantidos em sigilos e, representados pelas letras $\mathrm{P}$ (professor) e A (aluno). O quadro 1 mostra as etapas realizadas durante o período da pesquisa.

Quadro 1: Síntese das coleta de dados

\begin{tabular}{|c|c|c|c|c|}
\hline Instrumentos & Sujeitos & Finalidade & Período & Registro \\
\hline Datashow & $\begin{array}{l}\text { Professores } \\
\text { e alunos }\end{array}$ & $\begin{array}{l}\text { Apresentação } \\
\text { do } A p p\end{array}$ & 08.03.2016 & $\begin{array}{l}\text { Foram analisadas as características do } \\
\text { App. }\end{array}$ \\
\hline Datashow & Professores & $\begin{array}{l}\text { Formação } \\
\text { sobre o App }\end{array}$ & 08.03.2016 & $\begin{array}{l}\text { Foram observados a interação entre o } \\
\text { professor e o App, no qual perceberam que } \\
\text { o mesmo trata-se de um recurso auxiliar no } \\
\text { processo de Ensino e aprendizagem. }\end{array}$ \\
\hline App & $\begin{array}{l}\text { Professores } \\
\text { e alunos }\end{array}$ & $\begin{array}{l}\text { Apresentação } \\
\text { dos conteúdos }\end{array}$ & 22.03.2016 & $\begin{array}{l}\text { Foram analisados a importância do App } \\
\text { para o desenvolvimento e disseminação do } \\
\text { conteúdo para a facilitação no processo de } \\
\text { Ensino e Aprendizagem em Matemática. }\end{array}$ \\
\hline App & Alunos & $\begin{array}{l}\text { Aplicação em } \\
\text { sala de aula }\end{array}$ & $\begin{array}{c}22.03 .2016 \mathrm{a} \\
12.04 .2016\end{array}$ & $\begin{array}{l}\text { Foram analisados a complexidade do App } \\
\text { em sala e como o mesmo pode facilitar a } \\
\text { transmissão do conteúdo de forma dinâmica } \\
\text { e proativa. }\end{array}$ \\
\hline $\begin{array}{l}\text { Questões } \\
\text { abertas }\end{array}$ & Professores & $\begin{array}{l}\text { Realização da } \\
\text { entrevista }\end{array}$ & $\begin{array}{c}12.04 .2016 \mathrm{a} \\
26.04 .2016\end{array}$ & $\begin{array}{l}\text { Foram coletados a importância em inovar à } \\
\text { prática pedagógica, como sua } \\
\text { navegabilidade em sala de aula. }\end{array}$ \\
\hline $\begin{array}{l}\text { Questões } \\
\text { abertas }\end{array}$ & Alunos & $\begin{array}{l}\text { Realização da } \\
\text { entrevista }\end{array}$ & $\begin{array}{c}19.04 .2016 \mathrm{a} \\
26.04 .2016\end{array}$ & $\begin{array}{l}\text { Foram coletados a importância da } \\
\text { navegabilidade e dificuldade do App em } \\
\text { aulas de Matemática dentro e fora do } \\
\text { contexto escolar. }\end{array}$ \\
\hline
\end{tabular}

Fonte: Os autores (2016) 
A metodologia utilizada para analisar os dados da pesquisa foi mediada por análises textuais dos professores e alunos entrevistados. Conforme Lakatos e Marconi (2003, p. 31) afirmam que a análise textual "identifica-se como o texto em que apresenta um pensamento completo de cada pesquisador e nos possibilita uma visão rápida com a finalidade de evidenciar sua estrutura redacional".

\section{Reflexões e possibilidades do App Matemática Interativa para o processo de Ensino e Aprendizagem em aulas de Matemática}

O App Matemática Interativa, criado com o apoio da plataforma fábrica de aplicativos, teve o intuito em trabalhar o conteúdo "Trigonometria", tendo em vista a complementação no que se refere às relações Trigonométricas de Seno, Cosseno e Tangente. O objetivo proposto na utilização do App foi compreender como as TM podem contribuir no processo de ensino e aprendizagem em aulas de Matemática. O App foi utilizado com alunos da $3^{\underline{a}}$ série do Ensino Médio, no qual foi realizada uma seleção por meio de um convite e, os trinta primeiros alunos inscritos participaram da seleção e professores de Matemática.

O App Matemática Interativa foi apresentado aos professores em momentos oportunos, no qual participaram de uma formação e foram analisadas as características do App e a interação entre o professor, aluno e o App. A formação com os professores aconteceu no laboratório de informática da Escola no período de $4 \mathrm{~h}$ durante os encontros agendados. Os professores criaram seu próprio App, mas não foi planejado no momento com inserção de conteúdos para serem trabalhados em sala de aula. Durante a entrevista e a formação os professores analisaram a complexidade do App Matemática Interativa e como o mesmo pode facilitar o processo de construção do conhecimento.

O App foi utilizado em sala de aula de maneira planejada, o qual foi preciso impor limites para o aluno não tomar caminhos diferentes. É sabido que a 
dinâmica da utilização do App em sala de aula concerne ao momento exploratório de imagens, função seno, cosseno e tangente, e relações trigonométricas para facilitar o processo de ensino e aprendizagem de maneira dinâmica e eficaz.

O App não é muito utilizado no contexto educativo para auxiliar o aluno no processo de construção do conhecimento. Com o objetivo de utilizar as TM em sala de aula e aumentar a demanda de busca pelo conhecimento, o seu uso permitiu uma complementação de materiais que são utilizados em sala de aula. Com a demanda da utilização das TM por alunos em sala de aula, os professores precisaram impor a essa demanda, integrando em sua prática pedagógica, a fim, de ampliar o espaço para disseminação do conhecimento e interação.

$\mathrm{Na}$ entrevista realizada com os professores, questionamos sobre se era possível utilizar App como recurso acessível e para o apoio pedagógico em sala de aula que permite complementar o conteúdo dentro e fora do contexto escolar, de forma atrativa, dinâmica para o aluno aprender em qualquer hora e em qualquer lugar, e tais sujeitos revelaram que o App:

Pode ser sim, um recurso acessível e para o apoio pedagógico, tanto durante as aulas como uma fonte de pesquisa e em casa como complemento das aulas. (P1)

Esse aplicativo é bastante interessante para despertar o interesse dos alunos, podendo ser aplicado em sala de aula ou até mesmo em casa para estudos complementares. (P2).

Nunca utilizei, mas após visualizar e analisar as interfaces contidas no App verifico que é um ótimo complemento para aula. (P3).

O App proporciona um grande leque de opções para sua utilização, porém destacamos como principal atrativo, sua simplicidade e atratividade. (P4)

Variando sempre que necessário às ferramentas a fim, de tornar a aula mais interativa e dinâmica. (P5)

Com os alunos, também não foi diferente no momento da entrevista, quando perguntamos sobre a importância do App para a construção de conhecimento referente ao conteúdo que estava sendo trabalhado, e logo percebemos que para os alunos o App contribuiu na construção do conhecimento de forma dinâmica, no qual, o conteúdo disponível no aplicativo ajudou a tirar 
dúvidas e proporcionar uma nova forma de aprendizagem possibilitando o aluno a aprender em qualquer hora e em qualquer lugar, conforme revelam nas falas:

O App contribuiu em trazer conhecimentos e em tirar dúvidas em alguns assuntos. (A25)

Com a utilização do App na sala de aula aprendi os conteúdos, mas também a estudar de uma outra forma. (A26)

O App contribuiu muito em meu aprendizado, com ele aprendi fora da escola. (A31)

Observa-se que os professores e alunos reconhecem que o App é um ambiente interativo, no qual o aluno aprendeu de maneira dinâmica, além disso, o App pode ser um recurso para auxiliar o aluno e complementar os conteúdos estudados em sala de aula, com isso, percebeu-se que o uso do App proporcionou um leque de opções para o processo de construção do conhecimento. Nesse sentido, o professor percebeu a necessidade em inovar a prática pedagógica de forma criativa e com dinamicidade suas interfaces, pois, o App tratou-se de um recurso de fácil navegabilidade para utilização em sala de aula.

A estrutura do App é bem autoexplicativa. (P4)

Para utilizar o App não precisa um estudo específico para se utilizar cada interface. (P5)

Alunos e professores reconheceram que as interfaces do App são de fácil navegabilidade, percebemos que o professor não precisava ter conhecimentos técnicos para elaborar sua disciplina e disponibilizar para o aluno. Para que se tenha êxito ao utilizar o App em sala de aula é preciso ter planejamento para o sujeito interagir com o objeto de maneira que a interação entre o sujeito-objeto estimule $\mathrm{o}$ aluno a buscar o conhecimento.

O App pode ser utilizado como repositório de conteúdos, vídeos, informações, questões para o ENEM. Com isso, o professor precisava conhecer cada aba para utilizar de forma adequada, para que todos os alunos tivessem a 
oportunidade de conhecer que é proposto e complementar as informações em sua formação intelectual.

No entanto, quando o ambiente de aprendizagem é elaborado de forma planejado, e dinâmico, percebe-se que os alunos têm o desejo de voltar a utilizar para buscar conhecimentos através da pesquisa. Mas, é necessário organizar o ambiente para que as interfaces sejam bem proveitosas durante o processo de construção do conhecimento do aluno.

O App foi utilizado de forma inovável como fonte de pesquisa ou ainda pela facilidade de interação com o conteúdo podendo desta forma, ser uma biblioteca móvel para fontes de consultas. No entanto, o App tornou a aula atrativa, aproximando o aluno do conhecimento, da realidade e que possibilitou ao professor instigar o aluno a pesquisa, ao pensamento crítico. E foi pensado como um recurso que minimizou a distância do alunado e a informação.

Com essas interfaces disponibilizadas no App, percebeu-se que foram utilizadas como apoio pedagógico, para que o aluno complementasse o conteúdo passado em sala de aula, podendo estudar em qualquer hora e em qualquer lugar. Portanto, o App foi um recurso que melhorou o processo de construção do conhecimento de maneira ativa, dinâmica e criativa, como revela a fala dos professores:

Diante do avanço tecnológico e a facilidade dos alunos ter sempre em mãos o celular, um aplicativo tem função de uma fonte de pesquisa sempre a mão. Seria um complemento do livro didático. Já que a maioria das escolas já tem internet. Porém, vejo uma dificuldade no quesito disciplina, eles tem dificuldade em saber a hora de estuda com o aplicativo é a hora de acessar outros sites e até mesmo assistir a aula do professor. É uma ótima ferramenta no processo de ensino a aprendizagem dos alunos (P1)

Sabemos que aprender Matemática não é fácil, é necessário que o professor inove sua metodologia de passar os conteúdos vem a calhar como um bom suporte pedagógico para auxiliar os discentes no processo ensino/aprendizagem. Como esse aplicativo é detalhado e fácil de manusear, desperta atenção discente criando um novo método para avaliar e saber o grau de conhecimentos adquiridos por parte dos estudantes no ensino de Matemática. (P2)

Primeiro as TM tem tudo que um professor precisa como um calendário e uma agenda, um App, ajudariam no planejamento da aula, pois, todas as 
anotações, organizações das aulas estaria arquivadas no App, exemplo: uma biblioteca, como: livros de apoio ao professor, vídeos, listas de exercícios que podem ser respondida no próprio aplicativo, entre outras atividades. (P3)

A partir do momento em que possibilita a divulgação de textos de forma mais dinâmica e atemporal. (P4)

Acredito que a possibilidade de desenvolvimento na prática pedagógica se dá pelo fato de podermos utilizar várias atividades diferenciadas num só lugar, ou seja, em único App. Além disso, é importante também porque os alunos já estão acostumados a usar as TM no dia-a-dia. (P5)

Percebemos que integrar o App na prática docente foi preciso um planejamento para que orientasse o aluno a buscar conhecimento de formas diferenciadas e que viesse despertar a atenção em várias atividades diversificadas do cotidiano em sala de aula através de vídeos, informações e divulgação de textos de forma atemporal e dinâmica.

Diante dos relatos dos professores sobre a utilização do App na prática pedagógica, o seu uso trouxe aspectos positivos no processo de construção do conhecimento, nos quais, sua contribuição foi inteiramente produtível se tratando da ideia construtiva e como recurso auxiliar não pode ser integralmente descartado.

\section{Considerações Finais}

A utilização das TM na sociedade contemporânea vem ampliando estratégias na difusão de informações e comunicação nos últimos anos. No contexto educativo não são diferentes, pois, o aluno estar sempre conectado através das TM. Assim, é possível encontrar soluções para inserir no contexto educativo para melhor utilizar, adequando como recurso auxiliar para o processo de ensino e aprendizagem.

A relevância do produto educacional App Matemática Interativa e sua utilização em sala de aula, como recurso que pode auxiliar o aluno no processo de construção do conhecimento, e tornou-se evidente, a partir do momento que este aplicativo trouxe contribuições positivas para o contexto educativo no ensino de Matemática a partir da possibilidade do aluno ser autônomo de sua 
aprendizagem na busca pelo conhecimento de forma híbrida, colaborativa e significante e, com uma nova forma de aprender. Nesse sentido, percebemos que - App Matemática Interativa despertou no professor e no aluno a curiosidade e o desejo em buscar informações para ensinar e aprender.

Utilizamos a fábrica de aplicativo para criação do App para utilizar como recurso de apoio no contexto educacional. Nesse sentido, depois de elaborado o produto educacional App Matemática Interativa, investigamos como o mesmo pode ser utilizado com um grupo de trinta alunos da $3^{a}$ série do Ensino Médio e cinco professores em uma Escola Estadual no município de Matriz de Camaragibe - AL.

A expectativa da utilização das TM em sala de aula permitiu ao professor um novo recurso para o uso em sua prática pedagógica, que tornasse o ensino de Matemática mais prático e dinâmico. Diante dessa facilidade que as TM proporcionam ao contexto educativo, o professor precisa ter cuidado ao utilizá-lo, pois o App se restringe a poucos aparelhos que as TM oferecem. Os únicos aparelhos que não se limitam ao sistema da fábrica de aplicativos são os Android, IOs e Windows.

A escolha da fábrica de aplicativos trouxe contribuições para a potencialização de desenvolvimento do $A p p$, considerando, que para a criação do App o usuário da plataforma não precisa ter conhecimentos técnicos, pois, o desenvolvimento se dá de maneira rápida e fácil. A plataforma fábrica de aplicativos apresenta flexibilidade para inserir na prática pedagógica de forma eficaz, para apresentação de conteúdo e melhorias no processo de formação de aprendizagem.

Durante as entrevistas realizadas com alunos e professores, verificamos que há uma necessidade em inovar a prática pedagógica para melhor promover o processo de ensino e aprendizagem. Sendo assim, precisamos inovar a prática pedagógica para que o ensino seja dinâmico, atrativo e que desperte no aluno o gosto pela disciplina.

Percebemos nas observações que a utilização do $A p p$ em aulas de Matemática, despertou no aluno o gosto pela disciplina. Foram disponibilizados no 
App textos e exercícios da área de Matemática e que faz parte do dia-a-dia do aluno. Nesse sentido, o acesso a essas informações potencializou a capacidade cognitiva do aluno para aprender de forma atrativa.

\section{Referências}

COLL C.; MONEREO, MC. Psicologia da educação virtual: aprender e ensinar com as tecnologias de informação e da comunicação. Porto Alegre. Artmed, 2010.

GIL, A. C. Métodos e técnicas de pesquisa social. 6. Ed. - São Paulo: Atlas, 2008.

GODOY, A.S. Pesquisa qualitativa: Tipos fundamentais. Revista de Administração de Empresas - ERA/EAESP/FGV, São Paulo, v. 35, n³. Mai/Jun. 1995.

LAKATOS, E.M.; MARCONI, E.M. Fundamentos de metodologia científica. $5^{a}$ ed. São Paulo: Atlas 2003.

MORAN, J. M. Novas tecnologias e mediação pedagógica/ José Manuel Moran, Marcos T. Masetto, Marilda Aparecida Behrens, $21^{\underline{a}}$ ed. rev. e atual. Capinas. Papirus, 2013.

SACCOL, A. M. M-Learning e u-learning: novas perspectivas das aprendizagens móvel e ubíqua. São Paulo. Pearson Prentice Hall, 2011.

SILVA, J.L.; OLIVEIRA, C.S. Ensino de física e o uso do Facebook como estratégia didática na sala de aula. Revista RAEC, vol, 4, №2, p. 35-42, dezembro, 2015. 